\title{
Evaluation of Ultrasonography and CT for Imaging of Head and Neck Pilomatricoma in Children and Adolescents
}

\author{
Seongjun Won $^{1 *}$, Ki Ju Cho ${ }^{1 *}$, Somi Ryu ${ }^{1}$, Ji-Hyun Seo ${ }^{2,4}$, Jong Sil Lee ${ }^{3,4}$, and Jung Je Park ${ }^{1,4 *}$ \\ Departments of ${ }^{1}$ Otorhinolaryngology-Head and Neck Surgery, ${ }^{2}$ Pediatrics, and ${ }^{3}$ Pathology, Gyeongsang National University Hospital, \\ Gyeongsang National University School of Medicine, Jinju; and \\ ${ }^{4}$ Institute of Health Science, Gyeongsang National University School of Medicine, Jinju, Korea
}

\author{
소아와 청소년에서 두경부에 발생한 모기질종 진단 시 초음파와 CT의 유용성 평가 \\ 원성준 $^{1 *} \cdot$ 조기주 $^{1 *} \cdot$ 류소미 ${ }^{1} \cdot$ 서지현 ${ }^{2,4} \cdot$ 이종실 $^{3,4} \cdot$ 박정제 $^{1,4 *}$ \\ 경상국립대학교 의과대학 경상대학교병원 ${ }^{1}$ 이비인후과학교실, ${ }^{2}$ 소아과학교실, ${ }^{3}$ 병리학교실, ${ }^{4}$ 경상국립대학교 의과대학 건강과학연구원
}

\author{
Received May 10, 2021 \\ Revised July 3, 2021 \\ Accepted July 14, 2021 \\ Address for correspondence \\ Jung Je Park, MD, PhD \\ Department of Otorhinolaryngology- \\ Head and Neck surgery, \\ Gyeongsang National \\ University Hospital, \\ Institute of Health Sciences, \\ Gyeongsang National University \\ School of Medicine, \\ 79 Gangnam-ro, Jinju 52727, Korea \\ Tel $+82-55-750-8698$ \\ Fax $+82-55-759-0613$ \\ E-mail capetown@hanmail.net \\ *These authors contributed equally \\ to this work.
}

Background and Objectives Pilomatricoma is a frequently diagnosed skin lesion of the head and neck that may often be misdiagnosed as other skin lesions. This study evaluated whether ultrasonography (USG) or computed tomography (CT) is the most helpful imaging modality for the accurate preoperative diagnosis of pilomatricoma in head and neck regions of children and adolescents.

Subjects and Method A retrospective review was conducted for 59 patients with pilomatricoma under the age of 19 years. All cases were pathologically confirmed with pilomatricoma in the head or neck.

Results Preoperative imaging examinations were performed with USG in six cases and with $\mathrm{CT}$ in nine cases. The accuracy of preoperative diagnosis was compared between three groups: 1) with clinical findings only, 2) with USG, and 3) with CT. The correct preoperative diagnosis was made in $18(30.5 \%)$ of the total of 59 cases. Using only clinical findings, $10(22.7 \%)$ out of 44 patients were diagnosed as pilomatricoma. With the addition of USG, pilomatricoma was diagnosed in $1(16.7 \%)$ out of six cases, whereas with the addition of CT, 7 (77.8\%) out of 9 cases $(77.8 \%)$ were diagnosed correctly. Preoperative diagnosis of pilomatricoma with CT imaging was more accurate than clinical findings only (vs. CT; odds ratio $[\mathrm{OR}]=11.900,95 \%$ confidence interval [CI] 2.126-66.615; $p=0.001$ ) or USG (vs. CT; OR=17.500, 95\% CI 1.223250.357; $p=0.020)$.

Conclusion In the preoperative diagnosis of pilomatricoma, imaging modalities such as CT and USG are helpful, with CT offering higher diagnostic accuracy and USG procedural benefits in younger children. Korean J Otorhinolaryngol-Head Neck Surg 2021;64(12):922-7

Keywords Adolescent; Children; Computed tomography; Pilomatricoma; Ultrasonography.

\section{Introduction}

In the evaluation of pediatric patients with a mass of the head or neck, a physical examination and assessment of the

This is an Open Access article distributed under the terms of the Creative Commons Attribution Non-Commercial License (https://creativecommons.org/licenses/by-nc/4.0) which permits unrestricted non-commercial use, distribution, and reproduction in any medium, provided the original work is properly cited. patient's history should be performed first, and following this, additional tests such as laboratory studies, radiologic studies, and invasive methods are needed to make an accurate diagnosis under the clinical impression. Radiologic imaging modalities such as ultrasonography (USG), CT, and MRI are commonly used. USG is relatively quick, cost-effective, and avoids ionizing radiation. MRI is considered better for soft 
tissue masses and also avoids ionizing radiation, whereas CT with intravenous contrast media is preferred in the case of suspected malignancy or infection. There is a need to carefully consider which imaging modality is most appropriate for the patient.

Pilomatricoma, which is also known as pilomatrixoma, is a superficial benign subcutaneous tumor that originates in cortical hair cells. This tumor occurs mainly in children and adolescents, and is frequently located in the head and neck region. With the exclusion of lymph nodes, they are the second most commonly excised superficial masses in children after epidermal inclusion cysts. ${ }^{1)}$ Pilomatricoma is frequently misdiagnosed, and it is often not considered in the differential diagnosis. Previous studies have reported that the preoperative diagnosis of pilomatricoma on the basis of patient history and physical examination findings is correct in less than 50\% of cases. ${ }^{2)}$ However, even though the accuracy of the preoperative diagnosis based on clinical findings may be low, imaging studies are not routinely performed in cases of pilomatricoma, although there have been several reports on the imaging of pilomatricoma using USG, CT, or MRI. Compared with USG, CT, and MRI are expensive, and sedation or anesthesia may be required for relatively young children. As MRI is more expensive and difficult to acquire than CT, especially in young children, we consider CT as the first-choice imaging modality if the benefit of MRI is not obvious. Therefore, USG and CT are frequently selected as imaging modalities for the diagnosis of pilomatricoma in our institution.

The purpose of this study was to evaluate the accuracy of USG and CT in the preoperative diagnosis of pilomatricoma in head and neck regions of children and adolescents, and to determine which of the two imaging modalities is the more helpful.

\section{Subjects and Methods}

This study involved a retrospective review of 59 patients under the age of 19 years who were pathologically confirmed with pilomatricoma in the head or neck. All patients underwent surgical resection of the head or neck tumor in Gyeongsang National University Hospital between January 2008 and December 2017. The patients' medical records included details on sex, age, clinical findings, preoperative diagnosis, pathologic results, and characteristics seen on USG or CT. This study was performed with the permission of the Institutional Review Board of Gyeongsang National University Hospital (number: GNUH 20-05-10). The requirement for informed patient consent was waived.

Preoperative imaging tests were performed on 15 of the 59 patients (6 USG, 9 CT). The images were evaluated for the following characteristics: size (maximum diameter), shape, margin, echogenicity on USG, and the presence of calcification on CT. The images were reviewed by one head and neck radiologist. The accuracy of the preoperative diagnoses were assessed according to the following three patient groups: 1) those with clinical findings only, 2) those with additional USG, and 3) those with additional CT. Statistical analysis was performed using chi-squared tests implemented using SPSS Statistics version 22.0 for Windows (IBM Corp., Armonk, NY, USA).

\section{Results}

Of the 59 patients diagnosed with pilomatricoma of the head and neck region, 35 (59.3\%) were female and 24 (40.7\%) were male. The age at diagnosis varied, with 8 being from 0-4 years old (13.6\%), 22 being from 5-9 years old (37.3\%), 17 being from $10-14$ years old (28.8\%), and 12 being from 15-19 years old (20.3\%). Thirty lesions (50.8\%) occurred in the neck, $15(25.4 \%)$ in the peri-auricular area, $10(16.9 \%)$ in the cheek, and $4(6.8 \%)$ in the eyelid. The maximum size of the tumors ranged from 0.3 to $3.2 \mathrm{~cm}$ (mean $1.26 \mathrm{~cm}$ ), with the tumor being $1 \mathrm{~cm}$ or less in 28 patients $(47.4 \%) 1-2 \mathrm{~cm}$ in 24 patients $(40.7 \%)$, and more than $2 \mathrm{~cm}$ in 5 patients $(8.5 \%)$ (Table 1).

USG was performed on six patients, and presented the following findings: a well-defined margin with oval shape in 4 patients $(66.7 \%)$, a hyperechoic or isoechoic heterogeneous mass in 5 patients $(83.3 \%$ ), a peripheral hypoechoic rim in 3 patients (50.5\%), and posterior acoustic shadowing in 4 (66.7\%) patients. In the nine patients evaluated by $\mathrm{CT}$, all cases showed a well-marginated subcutaneous mass adherent to the overlying skin, and in 7 cases (77.8\%) the CT images showed a variable amount of calcification within the mass. These results are summarized in Table 2.

Among the total of 59 patients, the correct preoperative diagnosis for pilomatricoma was made in 18 cases (30.5\%). The most common misdiagnoses were epidermal inclusion cyst $(n=26,44.1 \%)$, followed by dermatofibroma $(n=4,6.8 \%)$, lipoma $(n=3,5.1 \%)$, and others $(n=8,18.2 \%)$ including branchial cleft remnant, preauricular sinuses, sebaceous cyst, simple skin lesion, and inflammation. In the 44 patients for which the 
preoperative diagnosis was made according to the opinion of the doctor based on only clinical findings including characteristics of skin lesion, size, age and location, 10 cases (22.7\%) without imaging tests were correctly diagnosed as pilomatricoma before surgery. In the cases where a diagnosis was made with reference to USG, pilomatricoma was diagnosed in 1 case $(16.7 \%)$, with the other cases being diagnosed as epidermal inclusion cysts $(n=5)$. In nine patients where reference was made to CT before surgery, 7 (77.8\%) out of nine cases were diagnosed correctly, with the other two cases being misdiagnosed as epidermal inclusion cysts. When each group was compared statistically, preoperative diagnosis with CT imaging was more accurate than diagnoses made using clinical findings only or with the assistance of USG (clinical find-

Table 1. Patient demographics $(n=59)$

\begin{tabular}{lc}
\hline \multicolumn{1}{c}{ Characteristics } & Value \\
\hline Sex & \\
Male & $24(40.7)$ \\
Female & $35(59.3)$ \\
Age $(\mathrm{yr})$ & \\
$0-4$ & $8(13.6)$ \\
$5-9$ & $22(37.3)$ \\
$10-14$ & $17(28.8)$ \\
$15-19$ & $12(20.3)$ \\
Location of mass & \\
Neck & $30(50.8)$ \\
Pre-auricular area & $15(25.4)$ \\
Cheek & $10(16.9)$ \\
Eyelid & $4(6.8)$ \\
Size of mass (cm) & \\
$\leq 1$ & $28(47.4)$ \\
1-2 & $24(40.7)$ \\
$>2$ & $5(8.5)$ \\
Unknown (missed) & $2(3.4)$ \\
\hline Data a presented as $n(\%)$
\end{tabular}

Data are presented as $n(\%)$

Table 2. US and CT findings of the pilomatricoma cases included in this study ( $n=6$ and $n=9$, respectively)

\begin{tabular}{ll}
\hline \multicolumn{1}{c}{ Image characteristics } & Value \\
\hline Ultrasonographic features & \\
Well-defined ovoid margin & $4(66.7)$ \\
Hyperechoic or isoechoic heterogeneous mass & $5(83.3)$ \\
Peripheral hypoechoic rim & $3(50.0)$ \\
Posterior acoustic shadowing & $4(66.7)$ \\
CT findings & \\
Well-marginated subcutaneous mass & $9(100.0)$ \\
Adherent to the overlying skin & $9(100.0)$ \\
Variable amount of calcification & $7(77.8)$ \\
\hline
\end{tabular}

Data are presented as $\mathrm{n}(\%)$ ings only vs. CT; odds ratio $[\mathrm{OR}]=11.900,95 \%$ confidence interval [CI] 2.126-66.615); $p=0.001$; USG vs. CT; OR=17.500, 95\% CI 1.223-250.357; $p=0.020$ ) (Table 3).

\section{Discussion}

Pilomatricoma was first reported as calcifying epithelioma of Malherbe by Malherbe and Chenantais in 1880. ${ }^{3)}$ In 1961, Forbis and Helwig) ${ }^{4}$ showed that it originates from the outer root sheath cell of the hair follicle, and it was renamed "pilomatrixoma," with both the terms "pilomatricoma" and "pilomatrixoma" having been widely used since 1977. ${ }^{3)}$ According to a previous study, pilomatricoma occurs commonly in the first and second decades of life, although it can also be found in other age groups. ${ }^{3)}$ Most studies show a female preponderance, with a female-to-male ratio of $3: 2 .^{3,5)}$ The clinical characteristics include a firm solitary painless slow-growing nodule, and often the presence of overlying skin discoloration, with a size-range of 0.5 to $3 \mathrm{~cm}$. ${ }^{6}$ It mainly occurs in the head and neck region, followed by the upper extremities, trunk, and lower extremities. In the head and neck region, the most common locations are the neck and the frontal, temporal, periorbital, and peri-auricular areas of the head. ${ }^{3,7,8)}$ In our study, the patient demographics were similar to those reported in the previous studies mentioned above, including patient gender and age, and the size and location of masses. The female-tomale ratio was also consistent with the previously reported ratio of 3:2. In most cases, pilomatricoma occurred between the ages of 5 and 14 years, with $37.3 \%$ of cases occurring between 5-9 years, and $28.8 \%$ between $10-14$ years; these find-

Table 3. Comparison of preoperative diagnoses with or without imaging

\begin{tabular}{lll}
\hline \multicolumn{1}{c}{ Group } & Pre-operative diagnosis & Value \\
\hline $\begin{array}{l}\text { Clinical findings only } \\
(\mathrm{n}=44)\end{array}$ & Pilomatricoma & $10(22.7)$ \\
& Epidermal inclusion cyst & $19(43.2)$ \\
& Dermatofibroma & $4(9.1)$ \\
& Lipoma & $3(6.8)$ \\
With USG $(\mathrm{n}=6)$ & Others & $8(18.2)$ \\
& Pilomatricoma & $1(16.7)$ \\
With CT $(n=9)$ & Epidermal inclusion cyst & $5(83.3)$ \\
& Pilomatricoma & $7(77.8)$ \\
& Epidermal inclusion cyst & $2(22.2)$ \\
\hline
\end{tabular}

Data are presented as $\mathrm{n}(\%)$. Comparison between clinical findings only vs. with USG; OR=0.680 (0.071-6.515), $p=0.737$. Comparison between clinical findings only vs. with CT; OR= $11.900(2.126-66.615), p=0.001$. Comparison between USG vs. $C T ; O R=17.500$ (1.223-250.357), $p=0.020$. USG, Ultrasonography; OR, odds ratio 
ings are similar to those in a previous report, which noted a high incidence of this tumor in patients between 8 and 13 years-of-age. ${ }^{9)}$ The tumor size was less than $3 \mathrm{~cm}$ in nearly all patients, with it being less than $1 \mathrm{~cm}$ in 28 cases (49.1\%) and $1-2 \mathrm{~cm}$ in 24 cases (42.1\%). The masses were mainly located in the neck (50.8\%), followed by the periauricular area (25.4\%), cheek (16.9\%), and eyelid (6.8\%). In most cases, clinical features including characteristics of skin lesion, size, age and location consistent with pilomatricoma were shown, but it was difficult to make a differential diagnosis from other skin tumors using only clinical findings. ${ }^{10}$

In the case of a superficial benign skin lesion such as pilomatricoma, diagnostic tests and imaging studies are often ignored and surgical excision is directly performed. In some cases, it is possible to make a correct diagnosis of pilomatricoma using only clinical findings; however, the diagnostic accuracy rate for the preoperative diagnosis of pilomatricoma without imaging is not high, being only $22.7 \%$ in our study, and less than $49 \%,{ }^{11,12)} 33 \%,{ }^{13)}$ and $41 \%$ in previous studies. ${ }^{8)}$ As the accuracy of a diagnosis based on only clinical findings is not high, it is necessary to consider additional diagnostic and imaging tests. The differential diagnosis of head and neck pilomatricoma includes epidermal inclusion cysts, branchial cleft remnants, preauricular sinuses, adenopathy, sebaceous cysts, foreign body reaction, inflammation, and malignant soft tissue tumors. ${ }^{5}$ In our study, the misdiagnoses made when only clinical findings were used included epidermal inclusion cyst $(43.2 \%)$, dermatofibroma (9.1\%), lipoma (6.8\%), and others $(18.2 \%)$. Although the misdiagnoses of pilomatricoma are various, epidermoid cyst is the most commonly mistaken disease. Epidermoid cysts are firm, round, and mobile, and are covered with normal overlying skin. They also generally present in an older age group in both adolescents and adults. ${ }^{5)} \mathrm{Be}-$ cause of the similar characteristics between epidermal inclusion cysts and pilomatricoma, epidermal inclusion cysts are often not successfully differentiated from pilomatricoma, even when imaging studies are performed.

Relatively subcutaneous tumors like pilomatricoma are often not investigated with routine imaging studies. Previously, USG was the most common imaging modality used in the diagnosis of pilomatricoma, presenting the advantages of being a relatively fast, cheap, and noninvasive method for evaluating superficial masses. Moreover, because sedation is not required for the examination, USG has been recommended as an appropriate diagnostic method for younger children, especially for lesions on the head or neck. The previously reported
USG features of pilomatricoma include a well-defined ovoid hypoechoic heterogeneous mass with a hypoechoic rim with internal echogenic foci and posterior shadowing, located at the junction of the dermis and subcutaneous fat. ${ }^{2,8,13)}$ However, in our study, only one case (Fig. 1) showed all of the abovementioned USG findings, and only this case was diagnosed as pilomatricoma. In the other cases, pilomatricoma was not differentiated from epidermal inclusion cysts. Previous studies reported that the diagnosis of pilomatricoma using USG findings ranged from $47 \%-82 \%{ }^{8}$ ) however, the accuracy of the diagnoses made using USG in the patients included our study was lower than that of the diagnoses made using only clinical findings, although the difference was not statistically significant ( $p=0.680$ ) because of the low number of patients who underwent a USG examination. We therefore conclude that it is difficult to distinguish between epidermal inclusion cyst and pilomatricoma on USG examination.

The next most commonly used modality for the imaging of pilomatricoma is contrast-enhanced CT. The documented CT features of pilomatricomas typically include: 1) a welldefined subcutaneous mass with mild to moderate enhancement, 2) partial attachment to the overlying skin, and 3) various amounts of calcification (Fig. 2). ${ }^{3,7)}$ Features 1 and 2 were present in all cases imaged with CT in this study, whereas feature 3 was found in seven of nine cases for which pilomatricoma was accurately diagnosed. The other two cases did not show calcification, and it was not therefore possible to differentiate between epidermal inclusion cyst and pilomatricoma. CT images of pilomatricoma can show various degrees of calcification, which is an important feature for the differential di-

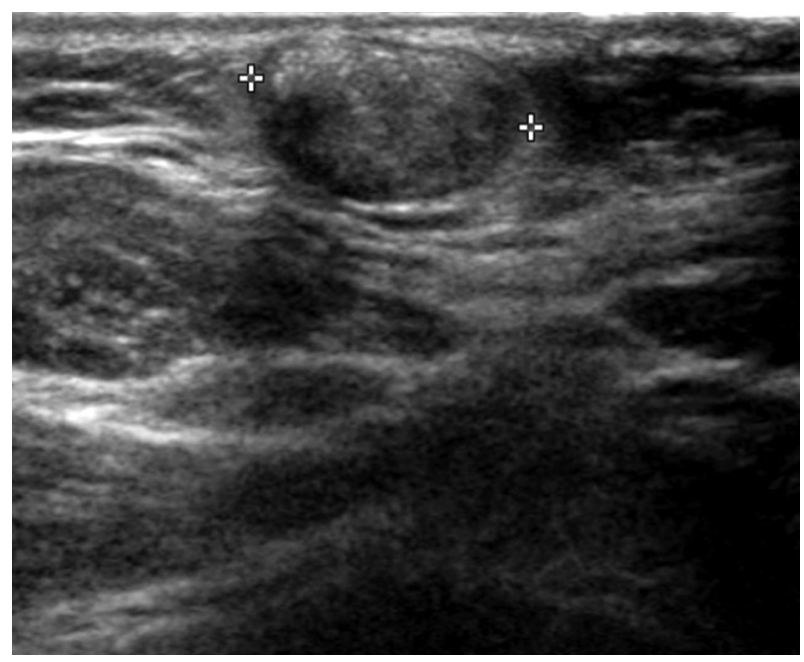

Fig. 1. Ultrasonography shows a well-defined isoechoic mass with a hypoechoic rim with posterior acoustic enhancement. 


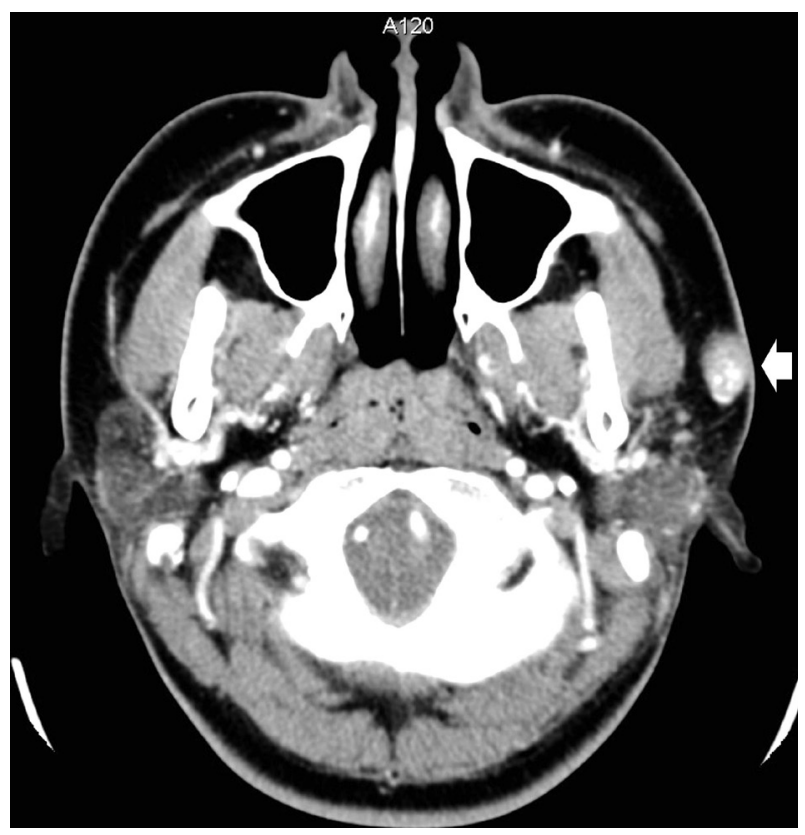

Fig. 2. Axial CT shows a well-marginated mass abutting the skin layer. Small nodular calcifications are visible in the mass (white arrow).

agnosis from epidermal inclusion cyst. CT shows a high diagnostic rate, which was reported as $87 \%$ by Lim, et al. ${ }^{8}$ Although CT is a very helpful diagnostic modality, it is difficult to perform in relatively young children, and the CT examination may require the use of a contrast agent and sedation or anesthesia, and will expose the patient to ionizing radiation. Therefore, if possible, the CT should be optimized to reduce the radiation dose to young children, with the dose depending on the age and size of the body. ${ }^{14}$

MRI and PET-CT imaging of pilomatricoma have also been reported. ${ }^{3,8}$ However, both MRI and PET-CT seem to offer little advantage over other tests because of their high cost, long test time, and the requirement for sedation or anesthesia.

In addition to imaging modalities, fine needle aspiration cytology (FNAC) has also been investigated for the pre-surgical diagnosis of pilomatricoma. However, the diagnostic rate of FNAC is not high, and it offers little advantage over other diagnostic methods. In the cytological analysis of pilomatricoma, the presence of basaloid cells, ghost cells, and giant cells is essential for the diagnosis, but these morphological aspects are not always disclosed in smears, ${ }^{15)}$ and are only seen in approximately $40 \%$ of FNAC cases. ${ }^{3)}$ Therefore, the diagnostic value of FNAC is not high, with previous reports of $41 \%$ and $44 \%$ of cases being correctly diagnosed by FNAC. ${ }^{3)}$ Furthermore, it should be kept in mind that FNAC is difficult to perform in young children because of the invasiveness of the test.
If malignancy is suspected, the need for imaging and fineneedle aspiration for a preoperative diagnosis is greater; however, malignant transformation of pilomatricoma is rare, and it has not been reported in children. ${ }^{5,7)}$

This study has limitations of a small number of subjects and a retrospective study. A small number of subjects affects the reliability of this study. And the possibility of selection bias also exists in retrospective study.

In conclusion, when a superficial tumor of the head or neck is seen in children and adolescents, pilomatricoma should be considered in the differential diagnosis. It is difficult to make a diagnosis of pilomatricoma using only clinical findings, and additional USG or CT examination may be necessary. As the characteristics of pilomatricoma on $\mathrm{CT}$ are more consistent than those on USG, CT is more helpful for obtaining a correct diagnosis. USG has a lower diagnostic rate than CT, although USG may be a more appropriate image modality for relatively younger children, offering the advantages of being non-invasive, free from exposure to ionizing radiation, and not requiring sedation. When considering an imaging study for the diagnosis of pilomatricoma, the most appropriate imaging modality should be chosen, keeping in mind that $\mathrm{CT}$ is more helpful for diagnosis, whereas USG offers procedural benefits for younger children.

\section{Acknowledgments \\ None.}

\section{Author Contribution}

Conceptualization: all authors. Data curation: all authors. Formal analysis: Seongjun Won, Ki Ju Cho, Ji-Hyun Seo, Jong Sil Lee, Jung Je Park. Investigation: Ki Ju Cho, Somi Ryu, Jong Sil Lee. Methodology: Ki Ju Cho, Somi Ryu, Jung Je Park. Project administration: Jong Sil Lee, Jung Je Park. Resources: Somi Ryu, Ji-Hyun Seo. Software: Ki Ju Cho. Supervision: Seongjun Won, Ji-Hyun Seo, Jung Je Park. Visualization: Jong Sil Lee. Writing — original draft: Ki Ju Cho, Somi Ryu. Writing_review \& editing: Seongjun Won.

\section{ORCID}

Jung Je Park https://orcid.org/0000-0001-6325-0398

\section{REFERENCES}

1) Knight PJ, Reiner CB. Superficial lumps in children: What, when, and why? Pediatrics 1983;72(2):147-53.

2) Bulman JC, Ulualp SO, Rajaram V, Koral K. Pilomatricoma of childhood: A common pathologic diagnosis yet a rare radiologic one. AJR Am J Roentgenol 2016;206(1):182-8.

3) Jones CD, Ho W, Robertson BF, Gunn E, Morley S. Pilomatrixoma: A comprehensive review of the literature. Am J Dermatopathol 2018;40(9):631-41

4) Forbis R, Helwig EB. Pilomatrixoma (calcifying epithelioma). Arch Dermatol 1961;83(4):606-18.

5) Danielson-Cohen A, Lin SJ, Hughes CA, An YH, Maddalozzo J. 
Head and neck pilomatrixoma in children. Arch Otolaryngol Head Neck Surg 2001;127(12):1481-3.

6) Agarwal RP, Handler SD, Matthews MR, Carpentieri D. Pilomatrixoma of the head and neck in children. Otolaryngol Head Neck Surg 2001;125(5):510-5.

7) Lan MY, Lan MC, Ho CY, Li WY, Lin CZ. Pilomatricoma of the head and neck: A retrospective review of 179 cases. Arch Otolaryngol Head Neck Surg 2003;129(12):1327-30.

8) Lim HW, Im SA, Lim GY, Park HJ, Lee H, Sung MS, et al. Pilomatricomas in children: Imaging characteristics with pathologic correlation. Pediatr Radiol 2007;37(6):549-55.

9) Chuang CC, Lin HC. Pilomatrixoma of the head and neck. J Chin Med Assoc 2004;67(12):633-6.

10) Higgins JC, Maher MH, Douglas MS. Diagnosing common benign skin tumors. Am Fam Physician 2015;92(7):601-7.
11) Moehlenbeck FW. Pilomatrixoma (calcifying epithelioma). A statistical study. Arch Dermatol 1973;108(4):532-4.

12) Yencha MW. Head and neck pilomatricoma in the pediatric age group: A retrospective study and literature review. Int J Pediatr Otorhinolaryngol 2001;57(2):123-8.

13) Hwang JY, Lee SW, Lee SM. The common ultrasonographic features of pilomatricoma. J Ultrasound Med 2005;24(10):1397-402.

14) Al Mahrooqi KMS, Ng CKC, Sun Z. Pediatric computed tomography dose optimization strategies: A literature review. J Med Imaging Radiat Sci 2015;46(2):241-9.

15) Ieni A, Todaro $P$, Bonanno AM, Catalano F, Catalano A, Tuccari G. Limits of fine-needle aspiration cytology in diagnosing pilomatrixoma: A series of 25 cases with clinico-pathologic correlations. Indian J Dermatol 2012;57(2):152-5. 